\title{
A Governança econômica global e os desafios do G-20 pós-crise financeira: análise das posições de Estados Unidos, China, Alemanha e Brasil
}

\author{
The global economic Governance and the challenges of the \\ G-20 after the financial crisis: an analysis of the positions of \\ the United States, China, Germany and Brazil
}

LEONARDO RAMOS*
JAVIER VADELL**
ANA SAGGIORO***
MÁRCIA FERNANDES****

Rev. Bras. Polít. Int. 55 (2): 10-27 [2012]

\section{Introdução}

A crise financeira de 2008 teve impactos significativos no capitalismo global, sendo um de seus reflexos na estrutura da governança global a constituição e evolução do G-20. Nesse contexto, o objetivo deste artigo é analisar tais mudanças nos mecanismos de governança e, em especial, as posiçôes de quatro dos principais atores nas cúpulas do G-20 no complexo processo de reconfiguração da ordem econômica mundial, a saber: Estados Unidos (EUA), República Popular da China, Alemanha e Brasil. Dentre outras razóes, tal escolha se deu pelo fato de os EUA, maior economia do mundo, e Alemanha, maior economia europeia, representarem a posição dos Estados capitalistas dominantes. A China é a potência econômica emergente de maior destaque e o novo motor do capitalismo global. A posição do Brasil é de extrema relevância para o nosso trabalho, já que permite mapear o papel do País nesse importante mecanismo de governança econômica global desde a crise financeira de 2008.

Em que medida a institucionalização do G-20 significa uma mudança substantiva no sistema de governança econômica global? Nossa hipótese é que,

\footnotetext{
* Professor do Departamento de Relaçôes Internacionais da Pontifícia Universidade Católica de Minas Gerais (PUC Minas) e Líder do Grupo de Pesquisa dos Países Emergentes da mesma instituição (lcsramos@pucminas.br).

** Professor do Departamento de Relaçōes Internacionais da PUC Minas e Líder do Grupo de Pesquisa dos Países Emergentes da mesma instituição (javier.vadell@gmail.com).

*** Pesquisadora do BRICS Policy Center do Instituto de Relaçôes Internacionais da Pontifícia Universidade Católica do Rio de Janeiro (PUC-Rio) e membro do Grupo de Pesquisa dos Países Emergentes da PUC Minas (anasaggioro@gmail.com).

**** Assistente de pesquisa do Departamento de Relaçôes Internacionais da PUC Minas e membro do Grupo de Pesquisa dos Países Emergentes da mesma instituiçăo (marcia_fernandes14@hotmail.com).
} 
a despeito da ação dos governos por meio da aplicação de estímulos monetários, fiscais e cambiais frente à crise de 2008, prevalecem as medidas de curto prazo e as respostas baseadas nos interesses nacionais. É verdade que, como era de se esperar, houve a incorporação de países como China, Índia e Brasil nas instituições de governança global. Não obstante, a legitimidade de tal incorporação é frágil e as soluções propostas nos últimos anos se parecem mais a acomodações e ajustes baseados em princípios liberais, mais flexíveis, para poder equacionar as complexas negociaçōes entre os membros do G-20, do que uma reestruturação das instituições visando à transformação da economia capitalista global.

Dessa maneira, em primeiro lugar, apresentar-se-á o processo de formação do G-20 a partir da ampliação do G-8 e os aspectos mais salientes das cúpulas do G-20, desde 2008. Logo depois analisaremos a posição dos EUA, da Alemanha, da China e do Brasil. Por fim, serão feitas algumas considerações finais a partir de tais levantamentos, apontando para perspectivas de mudanças na ordem mundial.

\section{G-20: o processo de formação}

Na Tabela 1, nota-se uma significativa ascensão do "resto" (Amsden 2004) desde os anos 1970, em contraposição à diminuição da participação dos países do G-8 na economia mundial. Há uma crescente relevância dos países emergentes na economia política global, o que faz com que sua inclusão nos mecanismos de governança a partir do final dos anos 1990 se torne algo cada vez mais impreterível. O estabelecimento de um lócus ampliado de discussão na área financeira, que incluísse o G-10 e mais alguns dos principais países em desenvolvimento, remete ao encontro dos ministros de finanças e presidentes de bancos centrais do G-7 em Halifax, em 1995 (Martinez-Diaz 2007). Nesse sentido, a crise asiática de 1997-1998 explicita algo que já emergia desde meados dos anos 1990, com a crise do México: as questões relacionadas ao sistema financeiro global não poderiam ser resolvidas exclusivamente pelo G-7, sendo fundamental incorporar os países "em desenvolvimento" ou "emergentes" em tais processos. Nesse contexto a ideia de um G-20 não era a única possibilidade viável nem era consensual entre os atores envolvidos. $\mathrm{Na}$ verdade, outras possibilidades foram trabalhadas na tentativa de ampliar o debate para os países em desenvolvimento.

Tabela 1. Produto Interno Bruto em comparação ao total mundial.

\begin{tabular}{|l|r|r|r|r|r|}
\hline \multicolumn{1}{|c|}{ Grupo } & 1970 & $\mathbf{1 9 8 0}$ & $\mathbf{1 9 9 0}$ & $\mathbf{2 0 0 0}$ & $\mathbf{2 0 0 8}$ \\
\hline G-8 & $71 \%$ & $64 \%$ & $68 \%$ & $66 \%$ & $55 \%$ \\
G-20 & $83 \%$ & $78 \%$ & $80 \%$ & $81 \%$ & $76 \%$ \\
O5 & $8 \%$ & $9 \%$ & $7 \%$ & $10 \%$ & $14 \%$ \\
G-20 sem G8 & $12 \%$ & $14 \%$ & $12 \%$ & $15 \%$ & $21 \%$ \\
\hline
\end{tabular}

Fonte: UNSTATS.

1 G-20 sem União Europeia. 
Destacam-se, assim, (a) a criação do Fórum de Estabilidade Financeira (FSF); (b) a formalização do comitê interino do FMI como Comitê Monetário e Financeiro Internacional (IMFC); (c) a proposta de criação de um mecanismo informal entre os países mais relevantes para a economia mundial, tendo como base o G-22 ou Willard Group criado em 1998². Após algumas reuniōes surgiu, em 1999, a proposta de expansão do G-22 para um G-33, que incorporaria principalmente países do Oriente Médio, da África e da Europa ${ }^{3}$. Nesse processo surgiram algumas insatisfaçóes e, no encontro de ministros de finanças do G-7, em setembro de 1999, foi estabelecido o G-20 ${ }^{4}$ como um fórum deliberativo que trabalhasse com base no consenso de seus membros (Kirton 2005) - fórum este que sofreu uma certa inflexão a partir da crise de 2008.

\section{As cúpulas a partir de 2008}

A crise econômica iniciada em 2008 teve uma peculiaridade: não ocorreu nos países em desenvolvimento, mas nos países centrais do capitalismo, e com proporçôes e desdobramentos mais amplos. Essa crise ativou um processo de transformação nos mecanismos de governança global: a perda de legitimidade do G-8, a ampliação das discussōes substantivas para o G-20 e o reforço e capitalização do FMI, embora com incertezas com relação a seu papel futuro. Assim, em 15 de novembro de 2008 ocorreu a primeira cúpula de líderes do G-20 em Washington que visava a "restaurar o crescimento global" (G-20 2008, \$1). Como atingir esse objetivo de amplo consenso seria o grande desafio.

A falta de mecanismos regulatórios suficientes para o setor das finanças e a falta de uma política de coordenação macroeconômica clara entre as maiores economias do mundo seriam as causas da crise. Assim, foi destacado o uso de medidas fiscais para estimular a demanda interna, o auxílio às economias emergentes e o fortalecimento, regulação e transparência das instituições financeiras privadas. (Ibidem, \$7). Além disso, foi colocada a questão da necessidade da reforma e capitalização das instituições financeiras mundiais. É reafirmado, assim, o FMI como um ator relevante neste processo. Além disso, amplia-se a representatividade do FSF (Ibidem, \$9).

2 Este foi criado pelos EUA e era composto por ministros de finanças e presidentes de bancos centrais de Canadá, França, Itália, Alemanha, Japão, EUA, Reino Unido, Argentina, Austrália, Brasil, China, Hong Kong, Índia, Indonésia, Malásia, México, Polônia, Rússia, Cingapura, África do Sul, Coreia do Sul e Tailândia.

3 Foram assim incluídos os seguintes países: Bélgica, Chile, Costa do Marfim, Egito, Marrocos, Holanda, Arábia Saudita, Espanha, Suécia, Suíça e Turquia.

4 Fazem parte do G-20: Argentina, Austrália, Brasil, Canadá, China, França, Alemanha, Índia, Indonésia, Itália, Japão, Coreia do Sul, México, Rússia, Arábia Saudita, África do Sul, Turquia, Reino Unido, EUA e Uniāo Europeia. Além disso, o diretor do FMI, o presidente do Banco Mundial, o presidente do Banco Central Europeu e o responsável pelo IMFC e pelo Comitê de Desenvolvimento do FMI têm status de observador no G-20. 
Nota-se que, se por um lado há um reconhecimento da necessidade de mudanças para ampliar a representatividade nas e a legitimidade das instituições internacionais, por outro há, explicitamente, uma reafirmação dos pontos fundamentais do modelo neoliberal que acabara de colapsar: o compromisso com o livre mercado, a propriedade privada e os mercados competitivos (Ibidem, \$12).

$\mathrm{Na}$ cúpula de Londres (2009), foi adotado o Conselho de Estabilidade Financeira (FSB) em substituição ao FSF, incluindo os países do G-20, exmembros do FSF, Espanha, e a Comissão Europeia - neste caso, a inclusão dos países emergentes foi o ponto fundamental da reforma (Idem 2009a). Na cúpula de Pittsburgh, em setembro de 2009, a economia mundial dava sinais de estabilidade dos mercados financeiros e de interrupção da queda das atividades econômicas. Houve em tal cúpula um comprometimento de que seriam desenvolvidas, “(...) até o final de 2010, normas acordadas internacionalmente para melhorar tanto a quantidade como a qualidade do capital bancário e desencorajar a alavancagem excessiva” (Idem 2009c, \$13). Nesta cúpula foi debatida uma reforma do FMI e do Banco Mundial, dando uma maior participação aos países emergentes. Com relação à questão do emprego houve uma certa inflexão, sendo enfatizada "a relevância da Conferência de Londres sobre Empregos e da Cúpula Social de Roma (...), [da] recém-adotada Resolução da OIT sobre Recuperação da Crise: um Pacto de Empregos Globais” (Idem 2009b, \$46).

$\mathrm{Na}$ cúpula de Toronto, em 26 e 27 de junho de 2010, foi reafirmada a relevância do G-20 como fórum privilegiado de discussão das questôes concernentes à economia global e à reestruturação da arquitetura financeira global. Destacam-se as questôes ainda não resolvidas, como a recuperação desigual e ainda frágil dos países, a permanência dos índices de desemprego em alguns países e o impacto social da crise na Europa, que atingiu a Grécia, Portugal, Espanha, Irlanda, Itália. Para isso, os países com economias deficitárias deveriam aumentar a poupança interna enquanto mantém os mercados abertos e aumentam sua competitividade de exportação e, os países emergentes superavitários deveriam "aumentar a flexibilidade da taxa de câmbio buscando refletir seus fundamentos econômicos subjacentes" (Idem 2010b, \$12). A "guerra cambial” entre China e EUA aparece como ponto de tensão nas declarações e continuaria tendo repercussōes para a próxima cúpula.

Em Pittsburgh no ano anterior (2009) houve um comprometimento de aumento do capital dos Bancos Multilaterais de Desenvolvimento (BMDs), o que ocorreu em Toronto (Tabela 2). Foi também endossada a reforma do Banco Mundial, que aumentou o poder de voto dos países em desenvolvimento em $4,59 \%$. 
Tabela 2. Aumento do capital dos Bancos Multilaterais de Investimento (BMD).

\begin{tabular}{|c|c|c|c|}
\hline BMD & Aumento de capital & $\begin{array}{l}\text { Empréstimos anuais antes } \\
\text { da crise }{ }^{5} \text { (em US\$ bilhões) }\end{array}$ & $\begin{array}{l}\text { Empréstimos anuais após } \\
\text { a crise }^{6} \text { (em US\$ bilhões) }\end{array}$ \\
\hline $\mathrm{AfDB}^{7}$ & $200 \%$ & 1,8 & 6 \\
\hline $\mathrm{AsDB}^{8}$ & $200 \%$ & 5,8 & 10 \\
\hline EBRD $^{9}$ & $50 \%$ & 5,3 & 11 \\
\hline $\mathrm{BID}^{10}$ & $70 \%$ & 6,7 & 12 \\
\hline BIRD $^{11}$ & $30 \%$ & 12,1 & 15 \\
\hline $\mathrm{IFC}^{12}$ & - & 5,4 & 17 \\
\hline Total & $85 \%$ & 37 & 71 \\
\hline
\end{tabular}

Fonte: G-20 (2010a, \$25; 2010c, \$5).

Na cúpula de Seul, em 11 e 12 de novembro de 2010, foram destacados os problemas do desemprego, bem como a necessidade de acelerar o crescimento. Neste sentido ressaltou-se, a importância do livre comércio e da abertura de mercados. Com relação às taxas de câmbio os EUA, além das constantes demandas com relação ao valor do yuan, anunciaram, na véspera da cúpula, que, nos oito meses seguintes, o Fed irrigaria a economia estadunidense com US\$ 600 bilhōes (Agência financeira 2010).

Em Seul foi acordada uma mudança nas cotas do FMI (ver tabela 3) e reafirmado o papel de destaque desta instituição na reconstrução da arquitetura financeira mundial. Para tal, seria necessário o aumento de sua capacidade de vigilância, bem como de seus dispositivos e linhas de crédito (G-20 2010d; 2010e). Neste processo, o FSB e BCBS também seriam centrais para estabelecer limites para a alavancagem dos bancos.

\footnotetext{
$5 \quad 2000-2008$.

$6 \quad 2012-2020$.

7 Banco de Desenvolvimento Africano.

8 Banco Asiático de Desenvolvimento.

9 Banco Europeu para Reconstrução e Desenvolvimento.

10 Banco Interamericano de Desenvolvimento.

11 Banco Internacional para Reconstrução e Desenvolvimento - parte do grupo do Banco Mundial.

12 Corporação Financeira Internacional - parte do grupo do Banco Mundial.
} 
Tabela 3. Distribuição de cotas - FMI.

\begin{tabular}{|c|c|c|c|c|}
\hline \multirow{3}{*}{ País/Grupo } & \multicolumn{4}{|c|}{ Ano } \\
\hline & \multicolumn{2}{|c|}{2009} & \multicolumn{2}{|c|}{$2010^{*}$} \\
\hline & Cotas (\%) & Votos (\%) & Cotas (\%) & Votos $(\%)$ \\
\hline EUA & 17,09 & 16,74 & 17,41 & 16,48 \\
\hline Reino Unido & 4,94 & 4,85 & 4,22 & 4,02 \\
\hline Japão & 6,12 & 6,01 & 6,46 & 6,14 \\
\hline Canadá & 2,93 & 2,88 & 2,31 & 2,21 \\
\hline França & 4,94 & 4,85 & 4,22 & 4,02 \\
\hline Itália & 3,24 & 3,19 & 3,16 & 3,02 \\
\hline Alemanha & 5,98 & 5,87 & 5,59 & 5,31 \\
\hline Federação Russa & 2,73 & 2,69 & 2,71 & 2,59 \\
\hline Total G8 & 47,97 & 47,08 & 46,08 & 43,79 \\
\hline Brasil & 1,40 & 1,38 & 2,32 & 2,22 \\
\hline África do Sul & 0,86 & 0,85 & 0,64 & 0,63 \\
\hline China & 3,72 & 3,65 & 6,39 & 6,07 \\
\hline índia & 1,91 & 1,88 & 2,75 & 2,63 \\
\hline México & 1,45 & 1,43 & 1,87 & 1,80 \\
\hline Total G5 & 9,34 & 9,19 & 13,97 & 13,35 \\
\hline Indonésia & 0,96 & 0,95 & 0,96 & 0,95 \\
\hline República da Coreia & 1,35 & 1,33 & 1,80 & 1,73 \\
\hline Argentina & 0,97 & 0,96 & 0,67 & 0,66 \\
\hline Arábia Saudita & 3,21 & 3,16 & 2,10 & 2,01 \\
\hline Turquia & 0,55 & 0,55 & 0,98 & 0,95 \\
\hline Austrália & 1,49 & 1,47 & 1,38 & 1,33 \\
\hline Total G-20 (sem UE) & 65,84 & 64,69 & 67,94 & 64,77 \\
\hline
\end{tabular}

* Decidido em novembro de 2010, mas será implementado apenas em 2012.

Fonte: FMI

Além disso, em consonância com Toronto, foi acordado em Seul o "Consenso de Seul”, no qual se destaca: a importância do crescimento econômico inclusivo e sustentável para a redução da pobreza; a ausência de uma única fórmula para o desenvolvimento e a ênfase no papel do setor privado na geração de empregos e riqueza (G-20 2010g).

Por fim, em Cannes, em novembro de 2011, as questôes vinculadas à crise da economia e governança global tomam novo impulso face à crise da Grécia e do Euro (Cooper 2011). As questões do emprego e da questão cambial, com referência direta à China ${ }^{13}$, voltam a aparecer. Neste contexto, com a crescente importância dos países emergentes, por um lado, e a crise do Euro de outro, foi destacada a necessidade de ampliação da cesta de moedas que compõem os Direitos

13 Menção explícita foi feita às ações de China e Rússia: "Congratulamos as mudanças recentes no regime cambial da Rússia que permite ao Rublo se mover de uma forma mais próxima das forças de mercado e a determinação da China em aumentar a flexibilidade da taxa de câmbio de uma maneira consistente com os fundamentos de mercado” (G-20, 2011b, \$3). 
Especiais de Saque - Special Drawing Rights $(\mathrm{SDR})^{14}$-, o que deverá ocorrer em 2015 (G-20 2011a).

\section{Posição dos países}

\section{Estados Unidos}

Em Washington, os EUA se posicionaram com desconfiança com relação aos planos de elaboração de uma nova ordem regulatória. Assim como o FMI, os EUA pressionaram os países a assumirem grandes déficits orçamentários, cortando impostos e incentivando o consumo. Já em Londres, os EUA buscaram influenciar os demais países do G-20 a implementarem programas de estímulo de, pelo menos, 2\% do PIB. Os países europeus - incluindo França e Alemanha - defenderam uma maior regulamentação financeira, e não o aumento de estímulos, o que levou os EUA a, informalmente, construírem um compromisso com a China e a França acerca dos paraísos fiscais. Neste contexto, duas questôes merecem destaque: primeiro, tais diferenças de posicionamento entre Europa e EUA foram, em larga medida, acomodadas pela administração do presidente Obama. Segundo, vários analistas anunciaram uma possível emergência de um "G-2", entre os EUA e a China.

Em Pittsburgh, as autoridades estadunidenses e europeias insistiram para que as autoridades econômicas das potências emergentes se envolvessem mais firmemente na concepção de um novo ordenamento econômico mundial. Em Toronto, os líderes dos países desenvolvidos do G-20, incluindo os EUA, se comprometeram a reduzir pela metade seu déficit nos próximos três anos - desde que tal medida não coloque em risco sua recuperação econômica mundial. Em tal cúpula, os EUA - juntamente com o Brasil e outros emergentes - não conseguiram convencer os países europeus a manterem suas políticas fiscais expansionistas para sustentar a retomada do crescimento mundial. Não obstante, na declaração final da reunião, há mudança de tom em relação aos documentos anteriores, com uma ênfase maior no crescimento.

Em Seul, o presidente dos EUA reafirmou a necessidade dos países com superávit em conta corrente - o que inclui China e Alemanha - aumentarem a sua demanda doméstica em vez de depender das exportações para se recuperar. Com o apoio de EUA e Alemanha, foi colocado no documento preliminar a necessidade de ampliar o compromisso para que os membros do G-20 "não adotem medidas que freiam a valorização de moedas justificadas pelos fundamentos do mercado" (G1 2010), numa clara referência à política cambial chinesa.

14 Trata-se da "moeda" do FMI ou, mais especificamente, da unidade contábil utilizada pelo FMI desde 1969. Atualmente sua cotação se dá com base em uma cesta de moedas composta por: Dólar estadunidense, Iene, Libra Esterlina, Euro. 
No Plano de Ação de Cannes para Crescimento e Emprego, além de reafirmar a situação delicada da economia mundial, o G-20 afirmou que nos EUA a recuperação econômica foi menor do que o esperado. Assim, os EUA se comprometeram a adotar um pacote de medidas de curto prazo para sustentar a recuperação. Do mesmo modo que a Alemanha, os EUA reafirmaram seu compromisso com as decisóes de Toronto no que diz respeito a planos de consolidação claros e credíveis, visando reduzir seu déficit até 2013, baseado nos índices de 2010, além de buscar reduzir a dívida pública até 2016. Especificamente, o país se comprometeu a reduzir de forma equilibrada sua dívida pública até a metade da atual década através da Lei de Controle do Orçamento de 2011. Estima-se que essas reformas reduzirão o déficit dos EUA em $\$ 4$ trilhões em cerca de 10 anos. O país também se comprometeu a aumentar a supervisão dos mercados de financiamento e a adotar medidas que permitam o aumento da poupança das famílias (G-20 Information Centre 2011).

Em relação ao aumento dos fundos destinados ao FMI, os EUA mantiveram em Cannes uma posição contrária, alegando que o fundo já possuía recursos suficientes (Bayne 2011). Neste sentido, juntamente com a França, enfatizaram a necessidade de maior flexibilidade cambial e da ampliação das moedas que sustentam os fundos de reserva do FMI.

\section{China}

A posição da China em Washington focou-se em quatro prioridades básicas: 1) uma ampla reforma no sistema monetário, nas instituições financeiras e nas regras e procedimentos das finanças internacionais; 2) uma reforma que contemple de maneira balanceada os interesses de todas as partes; 3) reformas incrementais que visem a um progresso gradual; 4) uma reforma orientada que objetive resultados práticos. As reformas deveriam contribuir para a estabilidade financeira internacional, o crescimento econômico global e o bem-estar das pessoas de todos os países.

Em Londres, a China focou em três pontos: medidas de curto e longo prazo para lidar com a crise econômica, a reforma do sistema financeira global e reforma do papel das instituiçôes financeiras globais. Ela pediu maior voz para os países emergentes e em desenvolvimento no sistema financeiro internacional na luta contra o protecionismo comercial e financeiro, e também foi favorável ao incremento dos gastos dos governos para estimular a economia. A China concordou com os países europeus na reforma do sistema financeiro internacional e apoiou a necessidade da criação de uma moeda de reserva internacional supra-soberana. Nesse sentido, o presidente do Banco Central Chinês expressou a necessidade de estimular o uso dos SDR como substituto do dólar. Alguns analistas sugerem que a China adota uma política de promoção da sua própria moeda, o yuan, como uma futura moeda de reserva, já que Beijing assinou acordos de "currency swaps" com seis Bancos Centrais: Hong Kong, Indonésia, Coreia do Sul, Malásia, Bielorrússia e Argentina 
(Pandey 2009). Para outros, como Eichengreen (2011) seria o contrário: a China seria o país mais interessado no fortalecimento do dólar, já que possui a maior reserva internacional de dólares no mundo.

$\mathrm{Na}$ Cúpula de Pittsburgh, ela se manifestou, mais uma vez, contra o protecionismo comercial e a favor de uma reforma do sistema financeiro internacional que desse mais voz aos países em desenvolvimento. A China propôs a criação de um "Fundo Soberano Global" para investir nos países em desenvolvimento. Não obstante, o diretor-geral de cooperação internacional da Comissão Nacional de Desenvolvimento e Reforma alertou que as políticas de estímulos econômicos "podem eventualmente gerar pressōes inflacionárias e enfraquecer as moedas” (Eckert 2009).

Em Toronto, China, EUA e Índia se posicionaram a favor de maiores estímulos para mitigar os efeitos da recessão europeia. A China concordou com o relativo fortalecimento da sua moeda na tentativa de mitigar a disputa sobre o valor do câmbio com os EUA. Além disso, como acordado em Pittsburgh, os países desenvolvidos aceitaram conceder maior poder de voto para as potências emergentes no FMI. A China destacou também a importância da ONU para os países em desenvolvimento e da retomada da rodada de Doha da OMC, opondose às práticas comerciais protecionistas.

Em Seul, ao ser pressionada pelos EUA e os países europeus para valorizar o yuan, a China afirmou que a crise de 2008 não foi provocada pela moeda chinesa ou por outra moeda dos países emergentes e que não aceitaria pressões nesse sentido. O foco da posição chinesa são os desequilíbrios do desenvolvimento global e a fraca regulamentaçãoo e supervisão dos capitais financeiros (China: FSB-G20 Monitoring Progress, 2011).

Há um consenso na imprensa internacional de que os países emergentes saíram fortalecidos na cúpula de Cannes. A crise da zona do Euro, e da Grécia em particular, desviou o foco das problemáticas sobre a reforma e coordenação da economia global. Neste cenário, a China se apresentou como peça chave para o equacionamento político da tragédia econômica europeia. O presidente Hu Jintao manifestou a necessidade de políticas de ganhos mútuos: "Neste momento crítico, o G-20 deve trabalhar para resolver os problemas chave, aumentar a confiança dos mercados, neutralizar os riscos, enfrentar desafios, e promover o crescimento econômico global e estabilidade financeira" (Xinhuanet 2011a). Além disso, o presidente chinês defendeu a coordenação de um novo sistema de governança global com maior protagonismo dos países emergentes - especificamente no que concerne ao sistema monetário internacional, no sistema de comércio internacional e nos mecanismos de preços das commodities (Idem 2011b). Não obstante, devido à gravidade da situação econômica da Europa, o papel da China no resgate e/ou ajuda à União Europeia (UE) foi um assunto recorrente, antes e durante a cúpula. A UE é o maior mercado para a China, o que a leva a ter muito interesse em manter uma situação econômica estável no velho continente. Mas há contrapartidas para 
essa ajuda, especialmente o reconhecimento da China como economia de mercado na OMC, e o fim do embargo de armas que se iniciou após a repressão na praça de Tiananmen na década de 1990 (Stephens 2011). Nessa direção, a China se comprometeu a ajudar a zona do Euro, não de maneira intergovernamental, mas sim por intermédio do FMI, posição que adquiriu força após ser consensuada entre os BRICS.

\section{Alemanha}

Em Washington, a Alemanha estava preocupada com a queda de suas exportaçõos, o que reforçou a posição de que a regulamentação dos mercados e a ação do Estado são importantes para garantir maior liquidez internacional. Em Londres, a Alemanha tinha a expectativa de convencer os países do G-20 a serem mais transparentes em relação aos seus mercados e aos centros offshore, e também mais rígidos nos controles dos mercados financeiros. Alemanha e Reino Unido concordavam que a solução para a crise também estava na reformulação do sistema bancário e buscavam promover uma articulação com o Banco Mundial, o FMI e bancos regionais para avaliar como essas instituiçôes poderiam desempenhar um papel mais relevante no empenho de conter a crise financeira.

Em Pittsburgh, a Alemanha defendeu uma regulamentação mais rígida nos mercados financeiros, bem como um novo equilíbrio entre estes e os Estados, além da criação de organizações supranacionais para auxiliar na condução desse equilíbrio. Ao término da cúpula, a Alemanha afirmou que os sistemas de regulação bancária internos deveriam ser modificados, o que foi criticado pelos EUA e pelo Reino Unido. A Alemanha era favorável à supervisão dos bancos alemães, no sentido de estarem sujeitos ao pagamento de bônus se assumirem altos riscos injustificáveis. Essas novas diretrizes foram a resposta da Alemanha às recomendaçôes da cúpula anterior do G-20 realizada em Londres. Em Pittsburgh a chanceler alemã pressionou pela adoção de tais medidas para implementar um plano global para o desenvolvimento econômico sustentável.

Tal questão foi retomada em Toronto quando a chanceler alemã defendeu a criação de um imposto nos mercados financeiros internacionais por considerar tal medida eficaz na redução da especulação internacional. Este imposto também seria usado como um fundo de resgate para socorrer os bancos que precisassem de ajuda futuramente.

Em Seul, a Alemanha ressaltou a falta de convergência entre China, EUA e União Europeia em relação à regulação do setor bancário e à reforma da regulação cambial. Neste contexto, reafirmou seu compromisso com as decisões de Toronto com relação à redução da dívida pública. Ademais, o país se comprometeu a adotar medidas capazes de incentivar o consumo privado e o investimento interno. É importante perceber que, nas cúpulas do G-20, a Alemanha tem, via de regra, apoiado as propostas da França. Os dois países atribuem à estrutura dos pacotes 
de compensação dos bancos a responsabilidade pela atual crise financeira pelo fato daquela ter estimulado a excessiva tomada de riscos que visava maximizar os lucros de curto prazo dos bancos à custa da própria estrutura destes.

Assim, Alemanha e França se reuniram antes da cúpula de Cannes e defenderam a criação de um imposto sobre as transações financeiras para os países europeus. Contudo, a negociação entre os dois países para alcançar uma solução para a crise europeia antes de Cannes não obteve êxito, o que fez com que a busca por esta solução ocupasse posição central na agenda da Cúpula. (Hilimoniuk 2011).

\section{Brasil}

O Brasil percebeu na crise de 2008 uma oportunidade para a mudança na estrutura do sistema financeiro e econômico internacional. $\mathrm{O}$ país atuou no processo de consolidação do G-20 como o principal foro para lidar com temas econômicos internacionais, e tem defendido a maior participação dos países emergentes nas instituiçõos de decisão sobre a economia mundial. Segundo o governo brasileiro, o G-20 teria aberto espaço ao Brasil para participação em outros foros, como IOSCO (Organização Internacional de Comissóes de Valores Mobiliários), FSB, BIS (Banco de Compensações Internacionais) e no processo de formulação do Acordo de Basileia III (Ministério das Relações Exteriores 2010a; 2010b).

Neste sentido, em Washington, o governo brasileiro declarou que o G-7 não tinha mais condições de guiar a saída da crise, tendendo a ser substituído pelo G-20. Além disso, o Brasil defendeu uma maior participação dos principais países em desenvolvimento nas instituições de governança global, bem como o fortalecimento do FMI e do Banco Mundial, desde que isso implicasse mudanças que elevassem o peso dos emergentes em tais instituições. O governo brasileiro declarou a intenção de adotar políticas anticíclicas, ao mesmo tempo em que buscaria manter o cumprimento das metas fiscais de superávit primário, definidas para 2008 e 2009. Por fim, se posicionou contra a proposta dos EUA de criação de novos mecanismos para gerar crescimento mundial equilibrado e sustentável.

Em Londres, o governo brasileiro propôs à China a utilização do Real e do Yuan no comércio bilateral, em substituição ao dólar. Houve também um posicionamento favorável com relação à política do FMI que visava assistir os países atingidos pela crise, com a ressalva de não reduzir as reservas internacionais do país. Neste contexto, o Brasil destacou a importância dos sistemas financeiros estarem vinculados à produção e à geração de emprego e renda bem como a necessidade de uma reforma dos organismos internacionais para que se construa um sistema internacional mais justo - visando a uma maior democratização das instituições financeiras e o combate aos paraísos fiscais.

Em Pittsburgh, o Brasil se declarou disposto a assumir uma posição de liderança em relação às normas internacionais de contabilidade na América Latina. Com relação às tensões entre os países desenvolvidos, o Brasil enfatizou 
sua preocupação com o fato de que a dificuldade de transposição de diferenças entre tais países prejudicasse as discussōes em torno da reforma das instituições financeiras internacionais. Neste contexto, o Brasil acabou por responsabilizar os EUA pelo bloqueio a negociação global de comércio.

Em Toronto, o Brasil, em acordo com os EUA, se opôs à proposta de taxação sobre o fluxo de capitais internacionais, apoiada pelos europeus. O governo brasileiro argumentou que tal proposta aumentaria os custos de financiamento e iria punir países que não foram responsáveis pela crise. Foram defendidas pelo país políticas anticíclicas que priorizem a retomada do crescimento, em contraposição às políticas de ajuste fiscal, especialmente da zona do euro, e um enrijecimento das medidas de supervisão e regulação bancárias. Houve também uma cobrança com relação à revisão no poder de voto no FMI - o que ocorreria em Seul.

Neste contexto, o Brasil rejeitou a imposição de uma taxa internacional sobre bancos, afirmando que o país já conta com regras de controle bancário mais rígidas que as dos EUA e as dos países europeus ${ }^{15}$. Além disso, o país se opôs ao esforço estadunidense de incluir na declaração final um apelo à retomada da rodada de Doha de liberalização comercial e defendeu a valorização do Yuan, com o intuito de não entrar em atrito com a China.

Em Seul, o Brasil propôs medidas de controle de fluxo de capital, juntamente com outros emergentes. Até então, o Brasil e outros nove países já haviam adotado algum tipo de controle de capital ${ }^{16}$. No caso brasileiro, houve o aumento do IOF (imposto sobre operação financeira). Neste contexto, as taxas de juros dos EUA, Europa e Japão eram quase zero, estimulando o "carry trade", ou seja, atores financeiros captam recursos nesses países a juros baixos e reaplicam em países com juros altos como o Brasil, ganhando sobre essa diferença, causando uma intensa entrada de capital no país e estimulando a valorização do Real. Assim, o Brasil propôs a criação de uma cesta de moedas no mercado externo, que inclua o Real e o Yuan, e que possa gradualmente substituir o dólar, no modelo dos SDR (Valor Econômico 2010b). Por fim, em Seul o Brasil se tornou o décimo cotista do FMI, passando de 1,3\% em 2008 para 2,32\% em 2010. Os BRICS, com os outros países associados, passaram para $11,55 \%$ dos votos, indicando um relativo aumento de importância, apesar de não lhes dar condição de veto com relação a temas que demandem $85 \%$ dos votos. Os EUA ficaram com 16,48\% dos votos, continuando assim com condiçõos de veto nas decisões mais importantes (tabela 3 ).

15 O Brasil exige dos seus bancos $11 \%$ de capital sobre o patrimônio de referência, enquanto o Banco de Compensaçôes Internacionais (BIS, na sigla em inglês) sugere 8\%. No entanto, não há, no Brasil, limites para remuneração dos executivos dos bancos - questão colocada na cúpula.

16 A Coreia do Sul restringiu as operaçōes com derivativos, a Indonésia limitou que investidores vendam alguns títulos de curto prazo, os bancos centrais de Israel à África do Sul estão comprando dólares para coibir a valorização de suas moedas e a China aumentou a exigência de compulsório dos bancos para desacelerar o investimento estrangeiro. Para maiores detalhes sobre o processo de implementação, por parte dos países, das recomendações feitas no âmbito do G-20, ver Financial Stability Board, 2012. 
Em oposição ao FMI e ao Banco Central Europeu, em Cannes a presidenta Dilma defendeu a taxação das operações financeiras mundiais como uma forma de financiar os investimentos sociais internacionalmente. Além disso, defendeu a criação de um programa mundial de renda mínima. Tal proposta já havia sido defendida pela OIT e, desta vez, contou também como o apoio da Argentina (Wasserman 2011). Além disso, houve certa divergência entre Brasil e China no tocante às questões de comércio internacional e normas sociais. No caso do comércio, o Brasil justificou sua postura comercial mais defensiva enquanto a China defendeu uma postura mais aberta se colocando contrária às políticas protecionistas. Já na questão trabalhista, a questão se inverteu: o Brasil defendeu a proposta da OIT de criação de um piso de proteção social por parte dos países do G-20 - o que foi visto com desconfiança por China e Índia (Valor Econômico 2011c; BRICS Policy Center/Núcleo de Sistemas de Inovação e Governança para o Desenvolvimento 2011).

Com relação à crise do Euro o Brasil propôs uma resposta coordenada entre os membros do BRICS. Tais países ajudariam a zona do Euro por meio de um fundo administrado pelo FMI, e não via compra de títulos europeus (Pereira 2011). Com relação às questôes cambiais, o Brasil se colocou a favor da proposta que foi expressa na declaração final.

\section{Considerações finais}

A emergência de novas potências mundiais, aliada à relativa diminuição da influência dos países desenvolvidos, coloca empecilhos para uma resolução da crise mediante mecanismos de governança global que levem em consideração apenas os interesses das potências ocidentais. Historicamente, as potências que tiveram capacidade de liderar saídas de situaçôes de caos sistêmico e crises globais se apresentaram como potências hegemônicas, construindo uma ordem mundial, de modo a tornar universais seus valores, regras, normas e interesses particulares (Arrighi 1993). Hoje, na atual situação de crise, nenhum país - sejam as potências tradicionais ou emergentes - mostrou capacidade de exercer esse papel de liderança e guiar uma saída para a crise a partir de seus moldes.

Alguns países emergentes, como Brasil, China, Índia, Coreia do Sul e México, já vêm desempenhando um papel decisivo em duas grandes áreas: demanda por um regime de comércio mundial mais aberto e gestão da crise econômica mundial com maiores controles aos fluxos de capitais. Durante as negociaçóes ministeriais na OMC em julho de 2008, o Brasil foi o negociador mais ativo. O fracasso nessas negociações deveu-se às discrepâncias do Brasil com a Índia, em torno à liberalização dos produtos agrícolas. Com relação à questão do controle aos fluxos de capitais, a proposta de liberalização foi recolocada pelos países desenvolvidos em Cannes, em 2011, com os países emergentes se colocando claramente contrários a tal proposta. 
$\mathrm{Na}$ cúpula de Londres, os EUA buscaram influenciar os demais países do G-20 a implementarem programas de estímulo de pelo menos 2\% do PIB. Não obstante, os países europeus - incluindo França e Alemanha - defenderam uma maior regulamentação financeira, e não o aumento dos gastos. Outras nações como o Japão, China, Índia e o Brasil permaneceram neutros, o que facilitou alguns avanços. Dias antes da cúpula de Londres o Diretor do Banco Central da China propôs que os SDR do FMI substituíssem o dólar como moeda de reserva, mas este tópico controverso não foi incluído na agenda da cúpula.

Embora tais exemplos apontem para uma falta de entendimento e de posições claramente convergentes, é possível perceber uma certa tendência, ainda incipiente e frágil, em direção à formação de duas grandes coalizões - ambas permeadas de clivagens e contradiçôes internas: de um lado, China, Brasil e os "novos emergentes", incluindo a Argentina (com a Coreia do Sul em uma posição de centro). Uma estratégia dos EUA para tentar cooptar países como o Brasil, por exemplo, é acusar a China de práticas cambiais desonestas ou manipuladas (Lacerda 2010). Em contraposição, e tendo em vista inclusive certas políticas cambiais unilaterais adotadas pelos EUA, a China acaba liderando determinadas propostas de alternativas monetárias ao dólar como reserva internacional - propostas que contam com certo apoio brasileiro. Além disso, a China responde às críticas dos EUA destacando a necessidade de que os países desenvolvidos implementem os compromissos feitos em Toronto - redução pela metade dos déficits até 2013 e estabilização ou redução da dívida em relação ao PIB até 2016.

Soma-se a tais questôes o fato de que os países emergentes são a favor do controle de capitais e contra a proposta dos países desenvolvidos para que haja uma redução do ritmo de acumulação de reservas internacionais (Valor Econômico 2010a; 2011b). Tal crítica dos países desenvolvidos é voltada para a China, pois as reservas dos BRICS somam cerca de US\$ 4 trilhões, dos quais US\$ 3,2 trilhões correspondem à China. Destaca-se, no caso do Brasil, a tentativa, em Cannes, de definir previamente certas posições comuns dos países latino-americanos (Calotti 2011) - Brasil, México e Argentina - sem, contudo, uma definição clara do futuro de tal tentativa de coalizão.

Do outro lado, os países desenvolvidos se encontravam em uma posição relativamente comum até a crise da Grécia. A partir de então, percebe-se uma certa fragmentação de tal bloco entre EUA e União Europeia. Os EUA se colocam contrários à regulamentação financeira, em consonância com os interesses do setor financeiro estadunidense, e favoráveis às políticas monetárias expansivas. Já a União Europeia, liderada pela Alemanha, é a favor de certos controles dos fluxos de capitais, com maiores ajustes fiscais monitorados pelo FMI na periferia da zona do Euro. Neste caso, o Brasil acaba se aliando à posição dos EUA, defendendo que os países desenvolvidos adotem políticas de estímulo à economia, e não políticas de contenção fiscal (Valor Econômico 2011a). 
Embora haja, desde a eclosão da crise em 2008, certa mudança no G-20 - o que se expressa na incorporação de temas até então negligenciados ou residuais na agenda das cúpulas do G-8, como a questão do emprego, por exemplo ${ }^{17}-$, é importante destacar que tal questão ocorre mais em um contexto de adequação e acomodação do modelo anterior, do que de transformação. Nesse sentido não há clareza acerca dos rumos e potencialidades transformativas que tais mudanças podem gerar. Ao mesmo tempo em que temas como desemprego e globalização a serviço das pessoas (e não somente dos mercados) entram na agenda, políticas de ajustes macroeconômicos de caráter eminentemente neoliberal são apresentadas nos documentos para os casos da Grécia, Portugal, Espanha e Itália, o que demonstra a complexidade e as contradições dos processos contemporâneos de transformação da ordem econômica mundial.

Assim, embora Brasil e demais países emergentes tenham hoje a possibilidade de incidir, em alguma medida, sobre as instâncias de decisão mundial, duas questôes merecem destaque: por um lado, os limites cooperativos entre os países emergentes, e por outro, mudanças como a das cotas do FMI acordadas em Seul, por exemplo, levam à conclusão de que, caso sua atuação continue sendo a de buscar reformas dentro das instituiçóes existentes corre-se o risco de perpetuar e aprofundar as próprias instituiçôes e os mecanismos de poder a elas associados.

\section{Referências bibliográficas}

Agência financeira (2010). EUA: Fed lança plano de estímulos de 600 mil milhōes. $<$ http://www.agenciafinanceira.iol.pt/mercados/fed-reserva-federal-eua-economia-retomaagencia-financeira/1205358-1727.html>. Disponibilidade: 2/2/2012.

CALOTTI, Gabriela.AméricaLatina chegaráao G20 deCannescom posiçōes comuns (2011).<http:// www.google.com/hostednews/afp/article/ALeqM5iN4NRSMN5sXkQzC992ki0wWiSZA?docId=CNG.e5ce6b411ed22ea916351951ba6e1993.151>. 11/10/2011. Disponibilidade: 2/2/2012.

AMSDEN, Alice H. (2004) A ascensão do "resto": Os desafios ao ocidente de economias com industrialização tardia. São Paulo: Unesp.

ARRIGHI, Giovanni (1993). The three hegemonies of historical capitalism. In: GILL, Stephen (ed.). Gramsci, historical materialism and International Relations. Cambridge: Cambridge University Press, p. 148-185.

B20 and L20 Joint Statement (2011). <http://www.g20.utoronto.ca/2011/2011-b20-120-en. html>. Disponibilidade: 17/11/2011.

BAYNE, Nicholas (2011). The G20 after the Cannes Summit Speaking Notes for the Paris Seminar. London School of Economics: Paris <http://www.g20.utoronto.ca/events/111107bayne.html>. Disponibilidade: 11/11/2011.

17 Vide, por exemplo, o documento conjunto entre sindicatos e setores de negócios quando da cúpula de Cannes (B20 and L20 Joint Statement, 2011). 
BRICS Policy Center/Núcleo de Sistemas de Inovação e Governança para o Desenvolvimento (2011). BRICS Monitor: G20 e o Brasil. <http://bricspolicycenter.org/homolog/uploads/ trabalhos/941/doc/434391267.pdf>.

China: FSB-G20 Monitoring progress (2011). <http://www.financialstabilityboard.org/ publications/r_110401e.pdf>. Disponibilidade: 2/2/2012.

COOPER, Andrew F. (2011). Up close at the Cannes Summit. <http://www.g20.utoronto.ca/ analysis/111105-cooper.html>. Disponibilidade:17/11/2011.

ECKERT, Paul (2009). China: é hora de começar a pensar em retirada de estímulos. 24/9/2009. <http://www.ccibc.com.br/pg_dinamica/bin/pg_dinamica.php?id_pag=5721>. Disponibilidade: $2 / 2 / 2012$.

EICHENGREEN, Barry (2011). Privilégio Exorbitante. Rio de Janeiro: Elsevier-Campus.

FINANCIAL STABILITY BOARD (2012). FSB report on the overview of progress in the implementation of the G20 recommendations for strengthening financial stability. <http:// www.financialstabilityboard.org/publications/r_111104.htm>. Disponibilidade: 2/2/2012.

G1 (2010). Dólar muda de direção e registra alta de 0,35\%. <http://g1.globo.com/ economia-e-negocios/noticia/2010/11/dolar-muda-de-direcao-e-registra-alta-de-035.html>. Disponibilidade: $2 / 2 / 2012$.

G-20 Information Center (2011). Cannes Action Plan for Growth and Jobs. <http://www.g20. org/Documents2011/11/Cannes\%20Action\%20plan\%204\%20November\%202011.pdf>. Disponibilidade: 11/11/2011.

G20 Labor and Employment Ministers (2010). Recommendations to G20 leaders. <http://www. dol.gov/ilab/media/events/G20_ministersmeeting/results.htm>. Disponibilidade: 24/12/2010.

G-20 (2008). Cúpula de líderes: Mercados financeiros e economia mundial. <http://www. g7.utoronto.ca/g20/2008/2008declaration1115-br.html>. Disponibilidade: 7/12/2010.

(2009a). Declaração dos líderes do G20 em Londres. <http://www.g7.utoronto.ca/ g20/2009/2009communique0402-br.html>. Disponibilidade: 7/12/2010.

(2009b). Declaração dos líderes: Cúpula de Pittsburgh. <http://www.g7.utoronto.ca/ g20/2009/2009communique0925-br.html>. Disponibilidade: 7/12/2010.

(2009c). Declaração dos líderes: Cúpula de Pittsburgh - Arcabouço para o Crescimento Forte, Sustentável e Equilibrado. <http://www.g7.utoronto.ca/g20/2009/2009communique0925br.html>. Disponibilidade: 7/12/2010.

(2010a). The G20 Toronto Summit declaration. <http://www.g7.utoronto.ca/ g20/2010/g20_declaration_en.pdf>. Disponibilidade: 7/12/2010.

(2010b). The framework for strong, sustainable and balanced growth. <http://www. g7.utoronto.ca/g20/2010/g20_declaration_en.pdf>. Disponibilidade: 7/12/2010.

(2010c). Enhancing the legitimacy, credibility and effectiveness of the IFIs and further supporting the needs of the most vulnerable. <http://www.g7.utoronto.ca/g20/2010/ g20_declaration_en.pdf>. Disponibilidade: 7/12/2010.

(2010d). The G20 Seoul Summit leader's declaration. <http://www.g7.utoronto.ca/ g20/2010/g20seoul.pdf>. Disponibilidade: 7/12/2010. 
(2010e). The Seoul Summit document. <http://www.g7.utoronto.ca/g20/2010/ g20seoul-doc.pdf>. Disponibilidade: 7/12/2010.

(2010g). Seoul Development Consensus for Shared Growth. <http://www.g7.utoronto. ca/g20/2010/g20seoul-consensus.pdf>. Disponibilidade: 7/12/2010.

(2011a). Cannes Summit Final Declaration - Building Our Common Future: Renewed Collective Action for the Benefit of All. <http://www.g20.utoronto.ca/2011/2011-cannesdeclaration-111104-en.html>. Disponibilidade: 17/11/2011.

(2011b). Cannes Action Plan for Growth and Jobs. <http://www.g20.utoronto. ca/2011/2011-cannes-action-111104-en.html>. Disponibilidade: 17/11/2011.

HILIMONIUK, Ryan (2011). 2011 G20 Plans and Preparations. <http://www.g20.utoronto. ca/g20plans/g20plans111030.pdf>. Disponibilidade: 11/11/2011.

INTERNATIONAL MONETARY FUND. <http://www.imf.org>. Disponibilidade: 2/2/2012.

KIRTON, John (2005). Toward multilateral reform: The G20's contribution. In:

ENGLISH, John, et al. (eds.). Reforming from the top: A leaders' 20 summit. Tokyo: United Nations University.

LACERDA, Antônio de Corrêa (2010). A guerra cambial e o Brasil. Valor Econômico, $8 / 11 / 2010$.

MARTINEZ-DIAZ, Leonardo (2007). The G20 after eight years: How effective a vehicle for developing-country influence? The Brookings institution, working paper $n^{\circ} 12$.

MINISTÉRIO DAS RELAÇŌES EXTERIORES. (2010a). G-20 financeiro. <http:// www.itamaraty.gov.br/temas/temas-multilaterais/governanca-global/g-20-financeiro $>$. Disponibilidade: $2 / 2 / 2012$.

(2010b). Balanço de Política Externa 2003-2010. <http://www.itamaraty.gov. br/temas/balanco-de-politica-externa-2003-2010/3.1.5-reforma-da-governanca-globalg20/?searchterm=G20>. Disponibilidade: $2 / 2 / 2012$.

PANDEY, Sheo Nandan (2009). China and the Diplomatic Power Play at G-20 London Summit. <http://www.southasiaanalysis.org/\%5Cpapers32\%5Cpaper3153.html>. Disponibilidade: $2 / 2 / 2012$.

PEREIRA, Ashley (2011). 2011 Cannes Summit Performance Assessment: Brazil. <http:// www.g20.utoronto.ca/analysis/111109-cannesperf-brazil.html>. Disponibilidade: 17/11/2011.

STEPHENS, Philip (2011). A Beijing cabby's view of the world. Financial Times. Disponibilidade: $3 / 11 / 2011$.

UNSTATS - United Nations Statistics Division. <http://unstats.un.org/unsd/default.htm>. Disponibilidade: 24/12/2010.

Valor Econômico (2010a). Brasil vai defender controle de capitais. Valor Econômico, 8/11/2010.

(2010b). Mantega defende trocar dólar por cesto de moedas no mercado externo. Valor Econômico, 10/11/2010.

(2011a). Brasil e EUA se aliam no G-20 a favor de estímulos. Valor econômico. $13 / 10 / 2011$.

$13 / 10 / 2011$

(2011b). BRICS rejeitam reduzir acumulação de reservas. Valor econômico. 
(2011c). Brasil e China adotam posturas opostas sobre comércio. 4/11/2011.

XINHUANET (2011a). O presidente chinês termina Cannes viagem após cúpula do G20. $<$ http://translate.google.com.br/translate?hl=pt-BR\&langpair=en\%7Cpt\&u=http://news. xinhuanet.com/english2010/china/2011-11/04/c_131230248.htm>. Disponibilidade: $5 / 11 / 2011$.

(2011b). Chinese President Hu's speech at G20 Summit in Cannes. <http://news. xinhuanet.com/english2010/china/2011-11/04/c_131228470.htm>. Disponibilidade: $5 / 11 / 2011$.

WASSERMAN, Rogerio (2011). Em Cannes, Dilma defende proposta da OIT para 'bolsa família’ global. <http://www.bbc.co.uk/portuguese/noticias/2011/11/111103_dilma_oit_ rw.shtml>. Disponibilidade: 17/11/2011.

Recebido em 6 de fevereiro de 2012

Aprovado em 4 de maio de 2012

\title{
Resumo
}

A crise financeira de 2008 teve impactos significativos no capitalismo global, sendo um de seus reflexos na estrutura da governança global a constituição e evolução do G-20. Neste contexto, o objetivo do artigo é analisar tais mudanças e, em especial, as posições de quatro dos principais atores nas cúpulas do G-20, a saber: Estados Unidos, China, Alemanha e Brasil.

Palavras-chave: crise financeira de 2008; G-20; governança econômica global.

\begin{abstract}
The 2008 financial crisis catalyzed transformations in the global capitalism that predicted the débâcle of the Anglo-American financial power bloc. One of the repercussions of such transformations is the evolution of the G-20. In this context, this article aims to analyze such transformations and, particularly, the role of four of the most important actors on G-20 summits: United States, China, Germany and Brazil.
\end{abstract}

Keywords: 2008 financial crisis; G-20; global economic governance. 